\title{
Engineering osteochondral constructs through spatial regulation of endochondral ossification
}

\author{
Eamon J. Sheehy ${ }^{1,2}$, Tatiana Vinardell ${ }^{1,2,3}$, Conor T. Buckley ${ }^{1,2}$, Daniel J. Kelly ${ }^{1,2 *}$
}

${ }^{1}$ Trinity Centre for Bioengineering, Trinity Biomedical Sciences Institute, Trinity College Dublin, Dublin, Ireland.

${ }^{2}$ Department of Mechanical and Manufacturing Engineering, School of Engineering, Trinity College Dublin, Dublin, Ireland.

${ }^{3}$ School of Veterinary Medicine, University College Dublin, Belfield, Dublin 4, Ireland.

\section{*Corresponding author}

E-mail address: kellyd9@tcd.ie

Address: Department of Mechanical and Manufacturing Engineering

School of Engineering

Trinity College Dublin

Dublin 2

Ireland

Telephone: +353-1-896-3947

Fax: +353-1-679-5554 


\begin{abstract}
Chondrogenically primed bone marrow derived mesenchymal stem cells (MSCs) have been shown to become hypertrophic and undergo endochondral ossification when implanted in vivo. Modulating this endochondral phenotype may be an attractive approach to engineering the osseous phase of an osteochondral implant. The objective of this study was to engineer an osteochondral tissue by promoting endochondral ossification in one layer of a bi-layered construct and stable cartilage in the other. The top-half of bi-layered agarose hydrogels were seeded with culture expanded chondrocytes (termed chondral layer) and the bottom half of the bi-layered agarose hydrogels with MSCs (termed osseous layer). Constructs were cultured in a chondrogenic medium for 21 days and thereafter were either maintained in a chondrogenic medium, transferred to a hypertrophic medium, or implanted subcutaneously into nude mice. This structured chondrogenic bi-layered co-culture was found to enhance chondrogenesis in the chondral layer, appearing to help re-establish the chondrogenic phenotype that is lost in chondrocytes during monolayer expansion. Furthermore, the bilayered co-culture appeared to suppress hypertrophy and mineralisation in the osseous layer. The addition of hypertrophic factors to the media was found to induce mineralisation of the osseous layer in vitro. A similar result was observed in vivo where endochondral ossification was restricted to the osseous layer of the construct leading to the development of an osteochondral tissue. This novel approach represents a potential new treatment strategy for the repair of osteochondral defects.
\end{abstract}

Keywords: Chondrocyte; msc; co-culture; hydrogel; osteochondral tissue engineering; endochondral. 


\section{Introduction}

Articular cartilage has a limited capacity for self-renewal and repair. Damage to the articular surface can penetrate to the subchondral bone and such osteochondral defects are often associated with mechanical instability of the joint and warrant surgical intervention in order to prevent osteoarthritic degenerative changes [1]. Even in cases where lesions do not penetrate to the subchondral bone an osteochondral construct may be a more desirable implant as a bone-to-bone interface integrates better than a cartilage-to-cartilage interface [2]. Autologous grafting procedures, such as mosaicplasty, are not ideal due to issues associated with topology conformity, donor site morbidity and tissue availability [3]. Tissue engineering applications aim to replace or regenerate damaged tissues through the combinations of cells, three-dimensional scaffolds and signalling molecules [4-5]. A number of strategies have been implemented to engineer osteochondral constructs including bi-phasic scaffolding [6-12], bioreactor technologies [13-16], and growth factor/gene delivery [17-20]. Engineered anatomically accurate osteochondral grafts have also been suggested as a potential approach to joint condyle repair [21-22].

It is possible to engineer functional cartilaginous tissues by embedding chondrocytes in three dimensional hydrogels [23-27]. Well documented limitations associated with chondrocytes [28-29] have led to increased interest in the use of mesenchymal stem cells (MSCs) for functional cartilage tissue engineering strategies [30-37]. A major challenge in MSC based cartilage repair therapies is the prevention of terminal differentiation as maintenance of the chondrogenic phenotype is critical in order to ensure the long-term in vivo stability of a cartilaginous graft [38]. When implanted subcutaneously in nude mice chondrogenically primed MSCs fail to produce cartilage resistant to hypertrophy and endochondral ossification, unlike fully differentiated chondrocytes which are capable of producing stable cartilage in vivo [39-40]. 
This apparent obstacle in MSC based cartilage tissue engineering has recently been realised as a potential advantage in bone regeneration applications with chondrogenically primed bone marrow derived MSCs being used to engineer bone in vivo via endochondral ossification [41-43]. One rationale as to why the endochondral route may be superior to the traditional intramembranous process for bone regeneration is that hypertrophic chondrocytes are programmed to withstand the initial hypoxic conditions a tissue engineered graft will experience once implanted in vivo [44]. In contrast, osteogenically primed constructs often fail due to excessive in vitro mineralisation of the extracellular matrix inhibiting vascular invasion and the associated delivery of oxygen and nutrients into the engineered tissue [45]. Another inherent advantage of chondrogenically primed MSCs for bone regeneration is that they are programmed to release factors that drive the mineralisation and vascularisation of the engineered tissue [44]. Modulating the endochondral phenotype of chondrogenically primed bone marrow derived MSCs may be an attractive approach to engineering the osseous phase of an osteochondral implant.

The objective of this study was to engineer an osteochondral tissue by promoting endochondral ossification in one layer of a chondrogenically primed bi-layered hydrogel and stable cartilage in another. Bi-layered hydrogels were fabricated by casting agarose seeded with chondrocytes (for the chondral layer) on top of agarose hydrogels seeded with MSCs (for the osseous layer). We hypothesised that by seeding the top layer of agarose hydrogels with chondrocytes and the bottom layer with bone marrow derived MSCs it would be possible to spatially restrict endochondral ossification to within the bottom layer both in vitro and in vivo following subcutaneous implantation in nude mice. 


\section{Materials and methods}

\subsection{Experimental design}

This study consisted of three experiments. Experiment 1 investigated the synergistic effects of a structured co-culture of chondrocytes and bone marrow MSCs, comparing chondrogenesis and terminal differentiation in single layer chondrocyte- and MSC- seeded agarose hydrogels with a bi-layered agarose hydrogel where the top layer is seeded with chondrocytes and the bottom layer with MSCs. All constructs were maintained in a chondrogenic medium (CM) supplemented with transforming growth factor- $\beta 3$ (TGF- $\beta 3$ ) for a period of 49 days (further details below). No studies were undertaken to explore if differentiation could be induced in the absence of this growth factor. Experiment 2 investigated whether a hypertrophic medium could be used to engineer an osteochondral construct in vitro and involved culturing bi-layered agarose hydrogels in a CM for a period of 21 days after which constructs were either maintained in a CM for an additional 49 days, or transferred to a hypertrophic medium (HM) with (+) or without (-) $\beta$-glycerophosphate supplementation. Experiment 3 investigated the possibility of spatially regulating endochondral ossification in vivo. This involved culture of single layer MSC-seeded agarose hydrogels and bi-layered agarose hydrogels in a CM for a period of 21 days after which constructs were implanted subcutaneously in nude mice for an additional 28 days. The experimental design is illustrated in Fig. 1.

\subsection{Cell isolation and expansion}

Chondrocytes and bone marrow derived MSCs were isolated from 4 month old porcine tissue as previously described [30]. Briefly, cartilage slices were rinsed with phosphate-buffered saline containing penicillin/streptomycin $(100 \mathrm{U} / \mathrm{mL})$ and digested by incubation with Dulbecco's modified Eagle's medium (DMEM) GlutaMax (Gibco, Biosciences, Dublin, 
Ireland) containing collagenase type II (315 U/mg; Worthington, Langanback Services) for 16-18 hours under constant rotation at $37^{\circ} \mathrm{C}$. Bone marrow derived MSCs were isolated from the femoral shaft. The colony unit forming - fibroblastic (CFU-f) assay was performed as previously described [46] on freshly isolated MSCs to calculate the colony forming unit efficiency. Upon isolation chondrocytes and bone marrow derived MSCs were seeded at a density of $5 \times 10^{3}$ cells $/ \mathrm{cm}^{2}$ in $175 \mathrm{~cm}^{2} \mathrm{~T}$ flasks, maintained in DMEM GlutaMax supplemented with $10 \%$ foetal bovine serum , $100 \mathrm{U} / \mathrm{mL}$ penicillin/streptomycin (both Gibco) and 5 ng/mL human fibroblast growth factor-2 (Prospec-Tany TechnoGene Ltd., Israel), and expanded to passage two ( 11 population doublings for chondrocytes and 14 population doublings for MSCs).

\subsection{Cell encapsulation in agarose hydrogels}

Expanded chondrocytes and MSCs were separately suspended in 2\% agarose (type VII; Sigma-Aldrich) at $\sim 40{ }^{\circ} \mathrm{C}$ and a density of $20 \times 10^{6}$ cells $/ \mathrm{mL}$ and cast in a stainless steel mould to produce cylindrical $(\varnothing 5 \times 3 \mathrm{~mm})$ single-layered constructs. Bi-layered constructs $(\varnothing 5 \times 3$ $\mathrm{mm})$ were fabricated by filling the bottom half $(1.5 \mathrm{~mm})$ of stainless steel moulds with MSC laden $2 \%$ agarose at $\sim 40{ }^{\circ} \mathrm{C}$ and allowing the agarose cell suspension to set (termed osseous layer). Thereafter the top half of the mould was filled with chondrocyte laden $2 \%$ agarose at $\sim 40{ }^{\circ} \mathrm{C}$ and left to set (termed chondral layer). The bottom surface of all bi-phasic constructs were cast on a hatch patterned poly-dimethyl-siloxane (PDMS) sheet so that both phases of the construct could be identified. All constructs were maintained in a chemically defined CM consisting of DMEM GlutaMAX supplemented with $100 \mathrm{U} / \mathrm{mL}$ penicillin/streptomycin (both Gibco), $100 \mu \mathrm{g} / \mathrm{mL}$ sodium pyruvate, $40 \mu \mathrm{g} / \mathrm{mL}$ L-proline, $50 \mu \mathrm{g} / \mathrm{mL}$ L-ascorbic acid-2phosphate, $4.7 \mu \mathrm{g} / \mathrm{mL}$ linoleic acid, $1.5 \mathrm{mg} / \mathrm{mL}$ bovine serum albumine, $1 \times$ insulintransferrin-selenium, $100 \mathrm{nM}$ dexamethasone (all from Sigma-Aldrich) and 10ng/mL of 
human transforming growth factor- $\beta 3$ (TGF- $\beta 3$ ) (Prospec-Tany TechnoGene Ltd., Israel) for 21 days. In experiment 1 all constructs were maintained in a CM for a further 28 days. In experiment 2, bi-layered constructs were either maintained in a $\mathrm{CM}$ or transferred to a hypertrophic medium, which constituted the removal of TGF- $\beta 3$, the addition of $1 \mathrm{nM} \mathrm{L-}$ thyroxine (Sigma-Aldrich) and a reduction in the level of dexamethasone to $1 \mathrm{nM}$, either with $(\mathrm{HM}+)$ or without (HM-) the supplementation of $20 \mu \mathrm{g} / \mathrm{ml} \beta$-glycerophosphate (SigmaAldrich), for a further 28 days [47].

\subsection{In vivo subcutaneous transplantation}

In experiment 3, following 21 days maintenance in a CM, single layer MSC- seeded constructs and bi-layered constructs were implanted subcutaneously into the back of nude mice (Balb/c; Harlan, Uk) as previously described [40]. Mice were euthanised 28 days after the surgery by $\mathrm{CO}_{2}$ inhalation. The animal protocol was reviewed and approved by the ethics committee of Trinity College Dublin.

\subsection{Biochemical analysis}

Constructs were sliced in half transversely and digested with papain $(125 \mu \mathrm{g} / \mathrm{mL})$ in $0.1 \mathrm{M}$ sodium acetate, 5mM L-cysteine-HCL, 0.05 M EDTA, pH 6.0 (all from Sigma-Aldrich) at 60 ${ }^{\circ} \mathrm{C}$ and $10 \mathrm{rpm}$ for $18 \mathrm{~h}$. DNA content was quantified using the Hoechst Bisbenzimide 33258 dye assay, with a calf thymus DNA standard. Proteoglycan content was estimated by quantifying the amount of sulphated glycosaminoglycan (sGAG) using the dimethylmethylene blue dye-binding assay (Blyscan, Biocolor Ltd., Northern Ireland), with a chondroitin sulphate standard. Total collagen content was determined by measuring the hydroxyproline content, using a hydroxyproline-to-collagen ratio of 1:7.69 [48-49]. Briefly, 
samples were mixed with $38 \%$ hydrochloric acid (Sigma-Aldrich) and incubated at $110^{\circ} \mathrm{C}$ for 18 hours to allow hydrolysis to occur. Thereafter samples were dried in a fume hood overnight and the sediment re-suspended in ultra pure $\mathrm{H}_{2} \mathrm{O}$. Chloramine $\mathrm{T}$ and 4(Dimethylamino)benzaldehyde (both Sigma-Aldrich) reagents were added and the hydroxyproline content quantified with a trans-4-Hydroxy-L-proline (Fluka analytical) standard using a Synergy ${ }^{\mathrm{TM}}$ HT (BioTek Instruments, Inc) Multi-detection micro plate reader at a wavelength of $570 \mathrm{~nm}$. 3-4 constructs were analysed per experimental group

\subsection{Histology and immunohistochemistry}

At each time point samples were fixed in $4 \%$ paraformaldehyde overnight, dehydrated in a graded series of ethanols, embedded in paraffin wax, sectioned at $5 \mu \mathrm{m}$ and affixed to microscope slides. The sections were stained with $1 \%$ alcian blue $8 \mathrm{GX}$ in $0.1 \mathrm{M}$ HCL to assess sGAG content, picro-sirius red to assess collagen distribution, and $1 \%$ alizarin red to assess calcium accumulation (all Sigma-Aldrich). Collagen types I, II and X were evaluated using a standard immunohistochemical technique; briefly, sections were treated with peroxidase, followed by treatment with chondroitinase ABC (Sigma-Aldrich) in a humidified environment at $37^{\circ} \mathrm{C}$ to enhance permeability of the extracellular matrix. Sections were incubated with goat serum to block non-specific sites and collagen type I (ab6308, 1:400; 1 $\mathrm{mg} / \mathrm{mL})$, collagen type II (ab3092, 1:100; $1 \mathrm{mg} / \mathrm{mL}$ ) or collagen type X (ab49945, 1:200; 1.4 $\mathrm{mg} / \mathrm{mL}$ ) primary antibodies (mouse monoclonal, Abcam, Cambridge, UK) were applied for 1 hour at room temperature. Next, the secondary antibody (Anti-Mouse IgG biotin conjugate, 1:200; $2.1 \mathrm{mg} / \mathrm{mL}$ ) (Sigma-Aldrich) was added for 1 hour followed by incubation with ABC reagent (Vectastain PK-400, Vector Labs, Peterborough, UK) for 45 min. Finally sections 
were developed with DAB peroxidase (Vector Labs) for $5 \mathrm{~min}$. Positive and negative controls were included in the immunohistochemistry staining protocol for each batch.

\subsection{Micro-computed tomography}

Micro-computed tomography $(\mu \mathrm{CT})$ scans were carried out on the in vivo specimens in order to quantify mineral content. A Scanco Medical $40 \mu \mathrm{CT}$ system (Scanco Medical, Bassersdorf, Switzerland) was used for evaluation with a $70 \mathrm{kVp} \mathrm{X-ray} \mathrm{source} \mathrm{and} 114 \mu \mathrm{A} .3$ constructs were analysed per experimental group.

\subsection{Statistical analysis}

All statistical analyses were carried out using Minitab 15.1. Results are reported as mean \pm standard deviation. Groups were analysed by a general linear model for analysis of variance with groups of factors. Tukey's test was used to compare conditions. Significance was accepted at a level of $p<0.05$. 


\section{Results}

\subsection{A structured bi-layered co-culture enhances chondrogenesis in the chondral layer of engineered constructs and suppresses hypertrophy and mineralisation in the osseous layer}

Cartilage specific matrix synthesis in constructs seeded only with chondrocytes or MSCs (termed single layer constructs) was compared to that in bi-layered constructs where the top layer was seeded with chondrocytes (termed chondral layer) and the bottom layer with MSCs (termed osseous layer). Chondrocytes synthesised significantly more sGAG compared to MSCs in both single layer constructs and in bi-layered constructs, see Fig 2. (a). A structured co-culture of chondrocytes and MSCs significantly enhanced collagen synthesis in the top chondral layer of bi-layered engineered constructs compared to single layer constructs that only contained chondrocytes $(133.32 \pm 21.8$ vs. $72.45 \pm 18.63 \mathrm{ng} / \mathrm{ng} ; \mathrm{p}<0.001)$. In contrast, MSCs in single layer constructs accumulated significantly more collagen compared to MSCs in the bottom osseous layer of bi-layered constructs $(154.65 \pm 14.53$ vs. $83.57 \pm 21.38 \mathrm{ng} / \mathrm{ng}$; p<0.001), see Fig. 2 (b). No significant increases in DNA levels were observed in single layer or bi-layered constructs over 49 days of in vitro chondrogenic culture (data not shown). All constructs stained positive for alcian blue, see Fig 3. Single layer MSC constructs also stained positive for alizarin red, a marker of mineralisation, around the construct periphery. No alizarin red staining was observed in the osseous layer of bi-layered constructs. In agreement with the biochemical analysis (Fig. 2), the chondral layer of bi-layered constructs stained more intensely for picro-sirius red compared to single layer chondrocyte constructs and the osseous layer stained weaker for picro-sirius red compared to single layer MSC constructs. Immunohistochemical analysis demonstrated stronger staining for type II collagen in the chondral layer of the bi-layered constructs compared to single layer chondrocyte constructs and weaker staining for type X collagen in the osseous layer compared to single layer MSC 
constructs, see Fig. 4. In general all constructs stained weakly for collagen type I accumulation.

\subsection{A hypertrophic medium induces in vitro mineralisation of the osseous layer of bi-layered} constructs

No evidence of mineralisation was observed in bi-layered constructs maintained in a hypertrophic medium without additional $\beta$-glycerophosphate supplementation (HM-). When $\beta$-glycerophosphate was added to the hypertophic medium $(\mathrm{HM}+)$, mineralisation of the osseous layer was observed as demonstrated by intense alizarin red staining, see Fig. 5 (a). Both hypertrophic media formulations resulted in apparent elongation of the interface between the osseous and chondral layer of bi-layered constructs. sGAG accumulation in the chondral layer of the engineered tissue was significantly reduced for constructs maintained in HM+ compared to CM, see Fig. 5 (b). No significant differences were observed in collagen accumulation between the CM, HM- and HM+ groups, see Fig. 5 (c). Mineralisation of the osseous layer correlated with significant cell death as evidenced by a reduction in the DNA content in this layer of bi-layered constructs when cultured in a hypertrophic medium with additional $\beta$-glycerophosphate supplementation (HM+), see Fig. 5 (d).

\subsection{Endochondral ossification can be spatially regulated in vivo}

Prior to subcutaneous implantation in nude mice both bi-layered and single layer MSC constructs stained positively for alcian blue. No mineralisation of the osseous layer of bilayered constructs had occurred prior to implantation whereas evidence of mineralisation was observed around the periphery of single layer MSC constructs, as evidenced by alizarin red staining, see Fig. 6 (a). Four weeks after subcutaneous implantation the chondral layer of bilayered constructs stained positive for alcian blue, with more intense staining observed in the 
deeper regions of this cartilage layer, see Fig. 6 (b). Endochondral ossification of the osseous layer had also commenced as evidenced by strong alizarin red staining around the base of the construct with negligible staining observed at the interface with the chondral layer. Single layer MSC constructs continued to mineralise in vivo with less intense alizarin red staining observed in the core of constructs. Mineral volume, quantified via $\mu \mathrm{CT}$ (Fig. 6 (b)), was significantly greater for single layer MSC constructs compared to bi-layered constructs (6.09 \pm 0.59 vs. $\left.1.36 \pm 0.42 \mathrm{~mm}^{3} ; \mathrm{n}=3 ; \mathrm{p}<0.001\right)$.

Bi-layered constructs weakly stained for collagen types I and X prior to implantation, see Fig. 7 (a). Single layer MSC constructs were positively stained for collagen type II but stained weakly for collagen types I and X prior to implantation. Post implantation, immunohistochemical analysis of bi-layered constructs demonstrated positive type II collagen staining in the chondral layer, with increased staining for collagen types I and $\mathrm{X}$ in the osseous layer compared to constructs pre-implantation, see Fig. 7 (b). Single layer MSC constructs demonstrated reduced collagen type II staining and increased collagen types I and $\mathrm{X}$ staining post implantation compared to pre- implantation. 


\section{Discussion}

This study examined the effect of a structured bi-layered co-culture on chondrogenesis of chondrocytes and bone marrow derived MSCs seeded in agarose hydrogels and tested the hypothesis that it is possible to engineer an osteochondral construct in vivo through spatial regulation of endochondral ossification. In vitro a structured bi-layered co-culture enhanced type II collagen synthesis by chondrocytes seeded in the top chondral layer of the bi-layered construct and reduced hypertrophy and mineralisation of MSCs in the bottom osseous layer. Mineralisation of the osseous layer of chondrogenically primed bi-layered constructs could be achieved in vitro through culture in a hypertrophic medium supplemented with $\beta$ glycerophosphate. Perhaps more importantly mineralisation of the osseous layer also occurred in vivo resulting in the development of an osteochondral construct consisting of a layer of stable cartilage on top of a layer of calcifying cartilage undergoing endochondral ossification.

Previous studies have demonstrated that in vitro hypertrophy of MSCs is inhibited through co-culture with chondrocytes [50-51], with parathyroid hormone-related protein secreted by chondrocytes proposed as one mechanism by which this suppression of terminal differentiation occurs [52]. In the present study a structured bi-layered chondrogenic coculture differentially regulated the synthesis of collagen by chondrocytes and MSCs within the construct. Immunohistochemical staining demonstrated reduced type $\mathrm{X}$ collagen accumulation in the osseous layer of bi-layered constructs while type II collagen accumulation increased in the chondral layer. This suggests that a structured bi-layered coculture suppresses hypertrophy of MSCs and enhances chondrogenesis of chondrocytes. Single layer chondrocyte seeded constructs stained weakly for collagen type II, indicating that a certain degree of de-differentiation had occurred prior to hydrogel encapsulation. Previous studies have demonstrated that chondrocytes lose their chondrogenic phenotype 
when expanded in monolayer [29]. Interestingly, a structured co-culture of chondrocytes and MSCs acted to help re-establish a chondrogenic phenotype in the expanded chondrocytes within the chondral layer of the bi-layered constructs. It has been reported that chondrogenically primed MSCs release growth factors and cytokines such as TGF- $\beta 3$, BMP2, IGF-1 and FGF-2 [53] and such soluble factors may play a role in enhancing chondrogenesis of chondrocytes co-cultured with MSCs [54-55]. Co-culture of chondrocytes and MSCs has also been shown to enhance proliferation of chondrocytes [54, 56], although such a phenomena was not observed in our bi-layered co-culture system. Direct cell to cell interaction may be required to drive the enhanced proliferation of chondrocytes when cocultured with MSCs [56], which is absent in our culture model as cells are separately encapsulated in the different regions of the hydrogel.

Even in a chondrogenic medium, single layer MSC seeded constructs tended to mineralise around their periphery. Previous studies have demonstrated that a higher oxygen tension exists in this region [57], with such high oxygen tensions known to enhance mineralisation of engineered cartilaginous constructs [46]. To accelerate such mineralisation, hypertrophic cartilaginous templates can be supplemented with $\beta$-glycerophosphate [47]. When bi-layered constructs were transferred to a hypertrophic medium supplemented with $\beta$ glycerophosphate, mineralisation of the MSC layer occurred whereas the chondrocyte seeded layer remained resistant to mineralisation. In hypertrophic media formulations, both with and without $\beta$-glycerophosphate supplementation, elongation of the interface between the two cell types was observed, suggesting perhaps that aspects of long bone growth are being mimicked in this culture system. The large reduction in DNA content in the mineralised phase of our bilayered construct cultured in the presence of $\beta$-glycerophosphate is also representative of endochondral bone formation where hypertrophic chondrocytes undergo apoptotic cell death [58]. 
Chondrogenically primed bone marrow derived MSCs have been shown to produce bone in vivo via endochondral ossification [41-43]. When implanted subcutaneously into nude mice the MSC layer of bi-layered constructs proceeded along the endochondral route with mineralisation progressing from the bottom of the construct. Previous studies exploring the fate of chondrogenically primed MSC pellets within a subcutaneous environment have observed a mineralised peripheral collar surrounding an inner cartilaginous region after 4 weeks in vivo which became almost completely resorbed by bone after 8 weeks in vivo [41]. Therefore the 4 week in vivo time point in our study may not have been sufficient to achieve complete endochondral ossification of the ossesous layer of the bi-layered constructs (see Fig. 6). When mineralisation of the osseous layer occurred in vivo no significant drop in DNA content was observed compared to pre-implantation levels (data not shown), unlike that seen upon transfer of bi-layered constructs to $\mathrm{HM}+$ in the in vitro study. This may be indicative of host cells invading the implant thus maintaining high levels of DNA content. Indeed host cells have been shown to play a key role in the endochondral ossification of cartilaginous templates [42-43]. It would also appear that the chondrocyte layer suppresses mineralisation of the MSCs located adjacent to the interface of the tissue. As mentioned previously this suppression may be a result of the secretion of anti-hypertrophic factors such as parathyroid hormone-related protein by chondrocytes in the chondral layer of the engineered construct. Further studies are required to determine if this suppression of endochondral ossification would occur at the construct interface in the long-term.

A critical question that remains to be answered is how this process of endochondral ossification would proceed within such a bi-layered construct within a defect of a load bearing joint. The subcutaneous environment differs in a number of notable ways to the orthotopic environment. Mechanical cues, absent in the subcutaneous environment, such as hydrostatic pressure [59-60] and dynamic compression [61-62] have been shown to play a 
role in regulating the endochondral phenotype of MSCs as well as matrix production [63]. The evolving intrinsic properties of the extracellular matrix may also play a role in driving this differentiation pathway [64]. Furthermore, the subcutaneous environment is well vascularised, which differs from the low oxygen microenvironment of articular cartilage. A low oxygen environment has been shown to suppress hypertrophy and markers of endochondral ossification in chondrogenically primed MSCs [46]. How such cues are integrated to regulate cell fate is a key question that needs to be addressed to enable any putative MSC-based therapy to be successfully used in the treatment of damaged and diseased joints.

Scaling-up of engineered grafts, and the associated nutrient diffusion and waste removal limitations, is a major challenge that will need to be overcome if the proposed engineered constructs are to be used in the treatment of large joint defects. Motivated by the fact that no biological based therapies exist to treat patients with osteoarthritis a number of studies have investigated engineering anatomically accurate osteochondral grafts for joint condyle repair [21-22, 65-66]. The endochondral approach described in this study may be a powerful tool in scaling-up the osseous phase of such grafts as it is possible to engineer large cartilaginous grafts in vitro using MSCs as the low oxygen conditions that develop within these constructs supports chondrogenic differentiation and the functional development of the engineered tissue [57]. Future studies in our lab will explore the potential of the proposed bilayered constructs to treat large scale osteochondral defects within the articular surface of load bearing joints.

\section{Conclusions}

In a structured bi-layered chondrogenic co-culture of chondrocytes and MSCs, chondrogenesis is enhanced in the chondrocyte seeded layer while hypertrophy and 
mineralisation is inhibited in the MSC seeded layer. Mineralisation of the osseous layer of such a bi-layered construct can be induced in vitro through culture in a hypertrophic medium supplemented with $\beta$-glycerophosphate or in vivo following subcutaneous implantation. Implanting chondrogenically primed bi-layered constructs containing chondrocytes and MSCs and spatially regulating endochondral ossification in vivo represents a promising new approach for the treatment of osteochondral defects.

\section{Acknowledgements}

This work was supported by Science Foundation Ireland under the President of Ireland Young Researcher Award (Grant No: SFI/08/Y15/B1336) and a starter grant from the European Research Council (StemRepair- Project No: 258463). 


\section{References}

1. Martin I, Miot S, Barbero A, Jakob M, Wendt D. Osteochondral tissue engineering. J Biomech. 2007;40(4):750-65.

2. Schaefer D, Martin I, Jundt G, Seidel J, Heberer M, Grodzinsky A, et al. Tissueengineered composites for the repair of large osteochondral defects. Arthritis Rheum. 2002 Sep;46(9):2524-34.

3. Grayson WL, Chao PH, Marolt D, Kaplan DL, Vunjak-Novakovic G. Engineering custom-designed osteochondral tissue grafts. Trends Biotechnol. 2008 Apr;26(4):181-9.

4. Langer R. Tissue Engineering. Mol Ther. 2000;1(1):12-5.

5. Koh CJ, Atala A. Tissue Engineering, Stem Cells, and Cloning: Opportunities for Regenerative Medicine. J Am Soc Nephrol. 2004;15(5):1113-25.

6. Gao J, Dennis JE, Solchaga LA, Awadallah AS, Goldberg VM, Caplan AI. Tissueengineered fabrication of an osteochondral composite graft using rat bone marrow-derived mesenchymal stem cells. Tissue Eng. 2001;7(4):363-71.

7. Oliveira JM, Rodrigues MT, Silva SS, Malafaya PB, Gomes ME, Viegas CA, et al. Novel hydroxyapatite/chitosan bilayered scaffold for osteochondral tissue-engineering applications: Scaffold design and its performance when seeded with goat bone marrow stromal cells. Biomaterials. 2006;27(36):6123-37.

8. Mano JF, Reis RL. Osteochondral defects: present situation and tissue engineering approaches. J Tissue Eng Regen Med. 2007;1(4):261-73.

9. Khanarian NT, Jiang J, Wan LQ, Mow VC, Lu HH. A hydrogel-mineral composite scaffold for osteochondral interface tissue engineering. Tissue Eng Part A. 2012;18(5-6):53345.

10. St-Pierre JP, Gan L, Wang J, Pilliar RM, Grynpas MD, Kandel RA. The incorporation of a zone of calcified cartilage improves the interfacial shear strength between in vitroformed cartilage and the underlying substrate. Acta Biomater. 2012;8(4):1603-15.

11. Rodrigues MT, Lee SJ, Gomes ME, Reis RL, Atala A, Yoo JJ. Bilayered constructs aimed at osteochondral strategies: The influence of medium supplements in the osteogenic and chondrogenic differentiation of amniotic fluid-derived stem cells. Acta Biomater. 2012;8(7):2795-806.

12. Theodoropoulos JS, De Croos JNA, Park SS, Pilliar R, Kandel RA. Integration of tissue-engineered cartilage with host cartilage: An in vitro model. Clin Orthop Relat Res. 2011;469(10):2785-95.

13. Wendt D, Jakob M, Martin I. Bioreactor-based engineering of osteochondral grafts: From model systems to tissue manufacturing. J Biosci Bioeng. 2005;100(5):489-94.

14. Mahmoudifar N, Doran PM. Tissue engineering of human cartilage and osteochondral composites using recirculation bioreactors. Biomaterials. 2005;26(34):7012-24.

15. Grayson WL, Bhumiratana S, Grace Chao PH, Hung CT, Vunjak-Novakovic G. Spatial regulation of human mesenchymal stem cell differentiation in engineered osteochondral constructs: Effects of pre-differentiation, soluble factors and medium perfusion. Osteoarthritis Cartilage. 2010;18(5):714-23.

16. Wang X, Grogan SP, Rieser F, Winkelmann V, Maquet V, La Berge M, et al. Tissue engineering of biphasic cartilage constructs using various biodegradable scaffolds: An in vitro study. Biomaterials. 2004;25(17):3681-8.

17. Mason JM, Grande DA, Barcia M, Grant R, Pergolizzi RG, Breitbart AS. Expression of human bone morphogenic protein 7 in primary rabbit periosteal cells: Potential utility in gene therapy for osteochondral repair. Gene Ther. 1998;5(8):1098-104. 
18. Guo X, Park H, Liu G, Liu W, Cao Y, Tabata Y, et al. In vitro generation of an osteochondral construct using injectable hydrogel composites encapsulating rabbit marrow mesenchymal stem cells. Biomaterials. 2009;30(14):2741-52.

19. Chen J, Chen H, Li P, Diao H, Zhu S, Dong L, et al. Simultaneous regeneration of articular cartilage and subchondral bone in vivo using MSCs induced by a spatially controlled gene delivery system in bilayered integrated scaffolds. Biomaterials. 2011;32(21):4793-805.

20. Guo X, Liao J, Park H, Saraf A, Raphael RM, Tabata Y, et al. Effects of TGF- $\beta 3$ and preculture period of osteogenic cells on the chondrogenic differentiation of rabbit marrow mesenchymal stem cells encapsulated in a bilayered hydrogel composite. Acta Biomater. 2010;6(8):2920-31.

21. Alhadlaq A, Elisseeff JH, Hong L, Williams CG, Caplan AI, Sharma B, et al. Adult stem cell driven genesis of human-shaped articular condyle. Ann Biomed Eng. 2004;32(7):911-23.

22. Alhadlaq A, Mao JJ. Tissue-engineered osteochondral constructs in the shape of an articular condyle. J Bone Joint Surg. 2005;87(5):936-44.

23. Mauck RL, Soltz MA, Wang CCB, Wong DD, Chao PHG, Valhmu WB, et al. Functional tissue engineering of articular cartilage through dynamic loading of chondrocyteseeded agarose gels. J Biomech Eng. 2000;122(3):252-60.

24. Mauck RL, Seyhan SL, Ateshian GA, Hung CT. Influence of seeding density and dynamic deformational loading on the developing structure/function relationships of chondrocyte-seeded agarose hydrogels. Ann Biomed Eng. 2002 Sep;30(8):1046-56.

25. Byers BA, Mauck RL, Chiang IE, Tuan RS. Transient exposure to transforming growth factor beta 3 under serum-free conditions enhances the biomechanical and biochemical maturation of tissue-engineered cartilage. Tissue Eng Part A. 2008 Nov;14(11):1821-34.

26. Buckley CT, Vinardell T, Kelly DJ. Oxygen tension differentially regulates the functional properties of cartilaginous tissues engineered from infrapatellar fat pad derived MSCs and articular chondrocytes. Osteoarthritis Cartilage. 2010;18(10):1345-54.

27. Vinardell T, Thorpe SD, Buckley CT, Kelly DJ. Chondrogenesis and integration of mesenchymal stem cells within an in vitro cartilage defect repair model. Ann Biomed Eng. 2009;37(12):2556-65.

28. Barbero A, Grogan S, Schäfer D, Heberer M, Mainil-Varlet P, Martin I. Age related changes in human articular chondrocyte yield, proliferation and post-expansion chondrogenic capacity. Osteoarthritis Cartilage. 2004;12(6):476-84.

29. Diaz-Romero J, Gaillard JP, Grogan SP, Nesic D, Trub T, Mainil-Varlet P. Immunophenotypic analysis of human articular chondrocytes: Changes in surface markers associated with cell expansion in monolayer culture. J Cell Physiol. 2005;202(3):731-42.

30. Vinardell T, Buckley CT, Thorpe SD, Kelly DJ. Composition-function relations of cartilaginous tissues engineered from chondrocytes and mesenchymal stem cells isolated from bone marrow and infrapatellar fat pad. J Tissue Eng Regen Med. 2011;5(9):673-83.

31. Sheehy EJ, Buckley CT, Kelly DJ. Chondrocytes and bone marrow-derived mesenchymal stem cells undergoing chondrogenesis in agarose hydrogels of solid and channelled architectures respond differentially to dynamic culture conditions. J Tissue Eng Regen Med. 2011;5(9):747-58.

32. Erickson IE, Huang AH, Chung C, Li RT, Burdick JA, Mauck RL. Differential maturation and structure-function relationships in mesenchymal stem cell- and chondrocyteseeded hydrogels. Tissue Eng Part A. 2009 May;15(5):1041-52.

33. Mauck RL, Yuan X, Tuan RS. Chondrogenic differentiation and functional maturation of bovine mesenchymal stem cells in long-term agarose culture. Osteoarthritis Cartilage. 2006 Feb;14(2):179-89. 
34. Thorpe SD, Buckley CT, Vinardell T, O'Brien FJ, Campbell VA, Kelly DJ. Dynamic compression can inhibit chondrogenesis of mesenchymal stem cells. Biochem Biophys Res Commun. 2008;377(2):458-62.

35. Thorpe SD, Buckley CT, Vinardell T, O'Brien FJ, Campbell VA, Kelly DJ. The response of bone marrow-derived mesenchymal stem cells to dynamic compression following tgf- $\beta 3$ induced chondrogenic differentiation. Ann Biomed Eng. 2010;38(9):2896-909.

36. Meyer EG, Buckley CT, Steward AJ, Kelly DJ. The effect of cyclic hydrostatic pressure on the functional development of cartilaginous tissues engineered using bone marrow derived mesenchymal stem cells. J Mech Behav Biomed Mater. 2011;4(7):1257-65.

37. Liu Y, Buckley CT, Downey R, Mulhall KJ, Kelly DJ. The role of environmental factors in regulating the development of cartilaginous grafts engineered using osteoarthritic human infrapatellar fat pad derived stem cells. Tissue Eng Part A. 2012;DOI:10.1089/ten.TEA.2011.0575.

38. Dickhut A, Pelttari K, Janicki P, Wagner W, Eckstein V, Egermann M, et al. Calcification or dedifferentiation: Requirement to lock mesenchymal stem cells in a desired differentiation stage. J Cell Physiol. 2009;219(1):219-26.

39. Pelttari K, Winter A, Steck E, Goetzke K, Hennig T, Ochs BG, et al. Premature induction of hypertrophy during in vitro chondrogenesis of human mesenchymal stem cells correlates with calcification and vascular invasion after ectopic transplantation in SCID mice. Arthritis Rheum. 2006;54(10):3254-66.

40. Vinardell T, Sheehy EJ, Buckley CT, Kelly DJ. A comparison of the functionality and in vivo phenotypic stability of cartilaginous tissues engineered from different stem cells sources. Tissue Eng Part A. 2012;DOI: 10.1089/ten.tea.2011.0544.

41. Scotti C, Tonnarelli B, Papadimitropoulos A, Scherberich A, Schaeren S, Schauerte A, et al. Recapitulation of endochondral bone formation using human adult mesenchymal stem cells as a paradigm for developmental engineering. Proc Natl Acad Sci U S A. 2010;107(16):7251-6.

42. Janicki P, Kasten P, Kleinschmidt K, Luginbuehl R, Richter W. Chondrogenic preinduction of human mesenchymal stem cells on $\beta$-TCP: Enhanced bone quality by endochondral heterotopic bone formation. Acta Biomater. 2010;6(8):3292-301.

43. Farrell E, Both SK, Odörfer KI, Koevoet W, Kops N, O'Brien FJ, et al. In-vivo generation of bone via endochondral ossification by in-vitro chondrogenic priming of adult human and rat mesenchymal stem cells. BMC Musculoskelet Disord. 2011;12.

44. Farrell E, Van Der Jagt OP, Koevoet W, Kops N, Van Manen CJ, Hellingman CA, et al. Chondrogenic priming of human bone marrow stromal cells: A better route to bone repair? Tissue Eng Part C Methods. 2009;15(2):285-95.

45. Lyons FG, Al-Munajjed AA, Kieran SM, Toner ME, Murphy CM, Duffy GP, et al. The healing of bony defects by cell-free collagen-based scaffolds compared to stem cellseeded tissue engineered constructs. Biomaterials. 2010;31(35):9232-43.

46. Sheehy EJ, Buckley CT, Kelly DJ. Oxygen tension regulates the osteogenic, chondrogenic and endochondral phenotype of bone marrow derived mesenchymal stem cells. Biochem Biophys Res Commun. [doi: 10.1016/j.bbrc.2011.11.105]. 2012;417(1):305-10.

47. Mueller MB, Tuan RS. Functional characterization of hypertrophy in chondrogenesis of human mesenchymal stem cells. Arthritis Rheum. 2008;58(5):1377-88.

48. Kafienah W, Sims TJ. Biochemical methods for the analysis of tissue-engineered cartilage. Methods Mol Biol. 2004;238:217-30.

49. Ignat'eva NY, Danilov NA, Averkiev SV, Obrezkova MV, Lunin VV, Sobol EN. Determination of hydroxyproline in tissues and the evaluation of the collagen content of the tissues. J Anal Chem. 2007;62(1):51-7. 
50. Cooke ME, Allon AA, Cheng T, Kuo AC, Kim HT, Vail TP, et al. Structured threedimensional co-culture of mesenchymal stem cells with chondrocytes promotes chondrogenic differentiation without hypertrophy. Osteoarthritis Cartilage. 2011;19(10):1210-8.

51. Bian L, Zhai DY, Mauck RL, Burdick JA. Coculture of human mesenchymal stem cells and articular chondrocytes reduces hypertrophy and enhances functional properties of engineered cartilage. Tissue Eng Part A. 2011;17(7-8):1137-45.

52. Fischer J, Dickhut A, Rickert M, Richter W. Human articular chondrocytes secrete parathyroid hormone-related protein and inhibit hypertrophy of mesenchymal stem cells in coculture during chondrogenesis. Arthritis Rheum. 2010;62(9):2696-706.

53. Sekiya I, Vuoristo JT, Larson BL, Prockop DJ. In vitro cartilage formation by human adult stem cells from bone marrow stroma defines the sequence of cellular and molecular events during chondrogenesis. Proc Natl Acad Sci U S A. 2002;99(7):4397-402.

54. Wu L, Leijten JCH, Georgi N, Post JN, Van Blitterswijk CA, Karperien M. Trophic effects of mesenchymal stem cells increase chondrocyte proliferation and matrix formation. Tissue Eng Part A. 2011;17(9-10):1425-36.

55. Tsuchiya K, Chen G, Ushida T, Matsuno T, Tateishi T. The effect of coculture of chondrocytes with mesenchymal stem cells on their cartilaginous phenotype in vitro. Mater Sci Eng C Mater Biol Appl. 2004;24(3):391-6.

56. Acharya C, Adesida A, Zajac P, Mumme M, Riesle J, Martin I, et al. Enhanced chondrocyte proliferation and mesenchymal stromal cells chondrogenesis in coculture pellets mediate improved cartilage formation. J Cell Physiol. 2012;227(1):88-97.

57. Buckley CT, Meyer EG, Kelly DJ. The influence of construct scale on the composition and functional properties of cartilaginous tissues engineered using bone marrowderived mesenchymal stem cells. Tissue Eng Part A. 2012;18(3-4):382-96.

58. Kronenberg HM. Developmental regulation of the growth plate. Nature. 2003;423(6937):332-6.

59. Steward AJ, Thorpe SD, Vinardell T, Buckley CT, Wagner DR, Kelly DJ. Cellmatrix interactions regulate mesenchymal stem cell response to hydrostatic pressure. Acta Biomater. [doi: 10.1016/j.actbio.2012.03.016]. 2012;8(6):2153-9.

60. Vinardell T, Rolfe RA, Buckley CT, Meyer EG, Ahearne M, Murphy P, et al. Hydrostatic pressure acts to stabilise a chondrogenic phenotype in porcine joint tissue derived stem cells. Eur Cell Mater. 2012;23:121-32; discussion 33-4.

61. Bian L, Zhai DY, Zhang EC, Mauck RL, Burdick JA. Dynamic Compressive Loading Enhances Cartilage Matrix Synthesis and Distribution and Suppresses Hypertrophy in hMSCLaden Hyaluronic Acid Hydrogels. Tissue Eng Part A. 2012;18(7-8):715.

62. Thorpe SD, Buckley CT, Steward AJ, Kelly DJ. European Society of Biomechanics S.M. Perren Award 2012: The external mechanical environment can override the influence of local substrate in determining stem cell fate. J Biomech. 2012.

63. Delaine-Smith RM, Reilly GC. The Effects of Mechanical Loading on Mesenchymal Stem Cell Differentiation and Matrix Production. Vitam Horm. 2011;87:417-80.

64. Reilly GC, Engler AJ. Intrinsic extracellular matrix properties regulate stem cell differentiation. J Biomech. 2010;43(1):55-62.

65. Hung CT, Lima EG, Mauck RL, Takai E, LeRoux MA, Lu HH, et al. Anatomically shaped osteochondral constructs for articular cartilage repair. J Biomech. 2003 Dec;36(12):1853-64.

66. Lee CH, Marion NW, Hollister S, Mao JJ. Tissue formation and vascularization in anatomically shaped human joint condyle ectopically in vivo. Tissue Eng Part A. 2009;15(12):3923-30. 


\section{Figure captions}

Fig. 1: Schematic of experimental design. MSC - Mesenchymal stem cell, CC Chondrocyte.

Fig. 2: Experiment 1: sGAG (a) and collagen (b) content normalised to DNA for single layer and bi-layer constructs cultured in chondrogenic medium for 49 days $(n=3-4)$. MSC Mesenchymal stem cell, CC - Chondrocyte. Significance $p<0.05$; a vs. single layer CC, b vs. single layer MSC, c vs. bi-layer MSC.

Fig. 3: Experiment 1: Histology for single layer and bi-layer constructs cultured in chondrogenic medium for 49 days. MSC - Mesenchymal stem cell, CC - Chondrocyte. One construct was sliced and stained per group.

Fig. 4: Experiment 1: Immunohistochemistry for single layer and bi-layer constructs cultured in chondrogenic medium for 49 days. MSC - Mesenchymal stem cell, CC - Chondrocyte. Brown staining indicates positive immunostaining. Black staining indicates non-specific staining, thought to be mineralised regions of the tissue. One construct was sliced and stained per group.

Fig. 5: Experiment 2: Histology (a) for single layer and bi-layer constructs cultured in chondrogenic medium for 21 days and then in hypertrophic medium either with (HM+) or without (HM-) $\beta$-glycerophosphate for an additional 28 days. One construct was sliced and stained per group. sGAG (b), Collagen (c), normalised to \% wet weight (\% ww), and DNA (d) content for bi-layer constructs cultured for 21 days in a chondrogenic medium and then in a chondrogenic medium (CM) or hypertrophic medium either with (HM+) or without (HM-) $\beta$-glycerophosphate for an additional 28 days $(n=3-4)$. Significance $p<0.05$; a vs. MSC layer, b vs. HM-, c vs. HM+. MSC - Mesenchymal stem cell, CC - Chondrocyte.

Fig. 6: Experiment 3: Histology (a) for single layer MSC and bi-layer constructs preimplantation (day 21). Histology and $\mu \mathrm{CT}$ analysis (b) for single layer MSC and bi-layer 
constructs post-implantation (day 49). $\mu \mathrm{CT}$ scale bar $=1 \mathrm{~mm}$. One construct was sliced and stained per group pre-implantation. Two constructs were sliced and stained per group postimplantation. Three constructs per group post-implantation were assessed by $\mu \mathrm{CT}$.

Fig. 7: Experiment 3: Immunohistochemstry for single layer MSC and bi-layer constructs pre- (a) and post- (b) implantation. Main images show high magnification images of the centre of constructs. Inset images show full constructs. Brown staining indicates positive immunostaining. Black staining indicates non-specific staining, thought to be mineralised regions of the tissue. One construct was sliced and stained per group pre-implantation. Two constructs were sliced and stained per group post-implantation. 

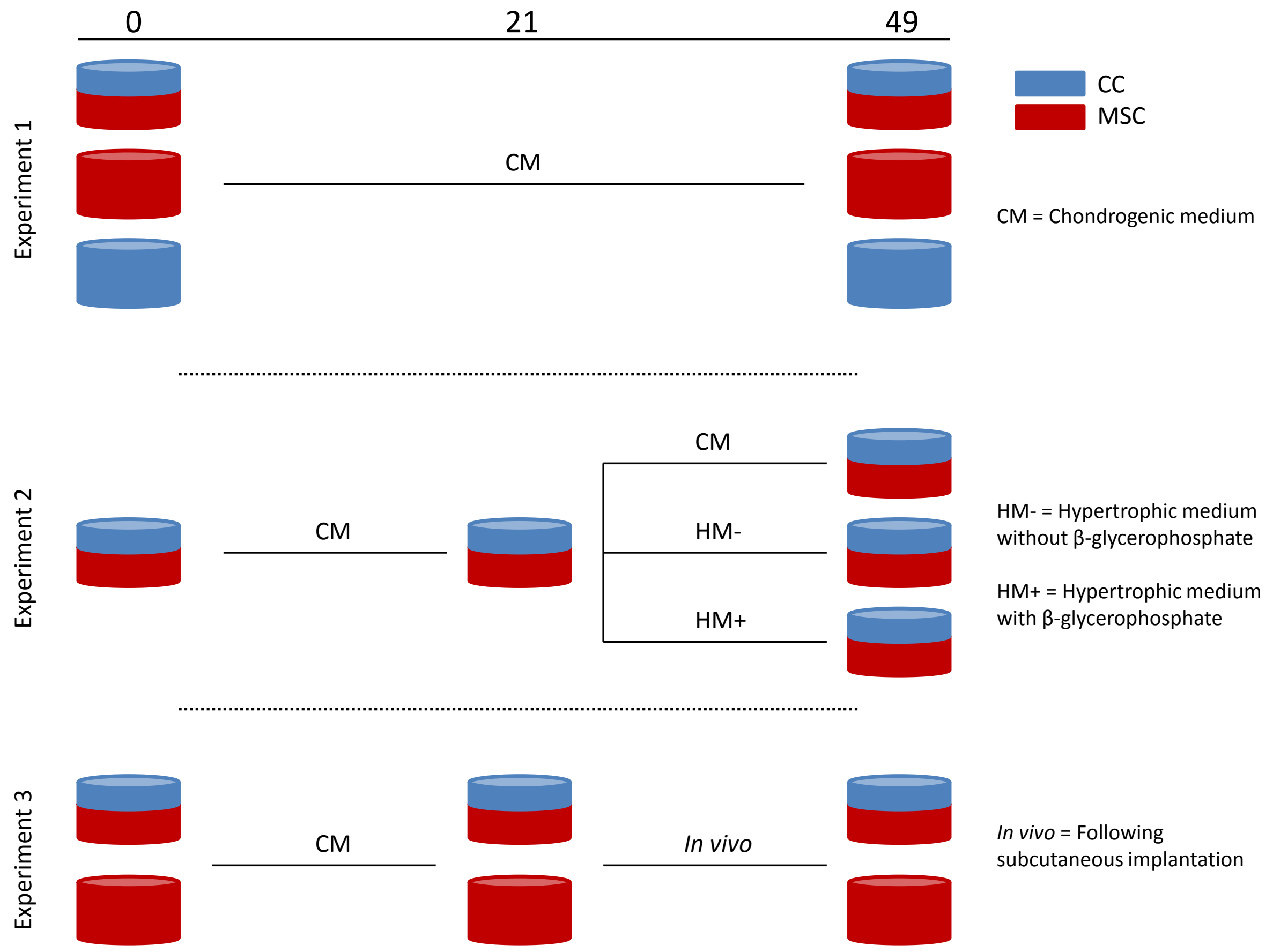

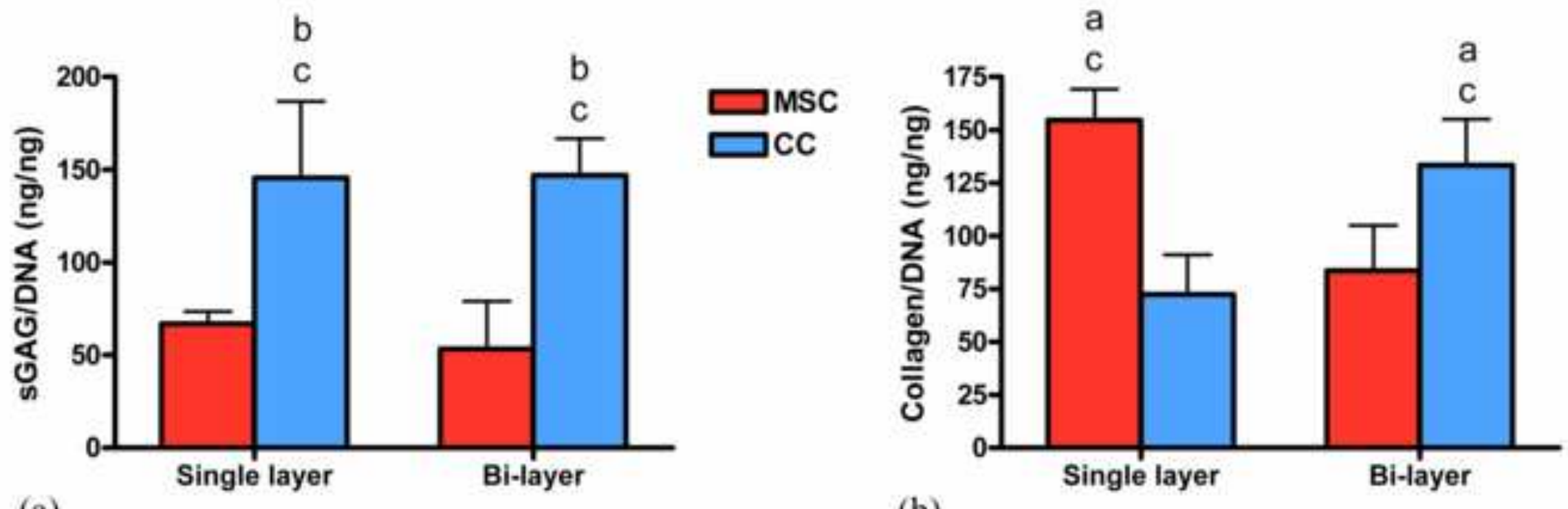

(a) 
Figure 3
Click here to download high resolution image

\section{Alcian blue}

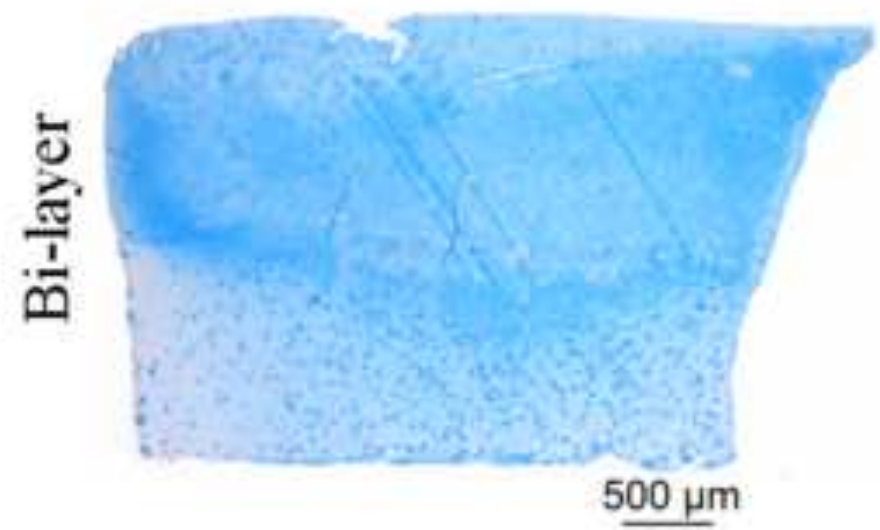

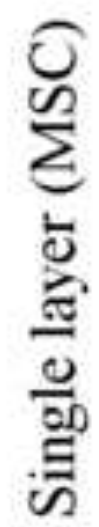

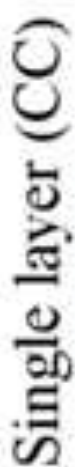

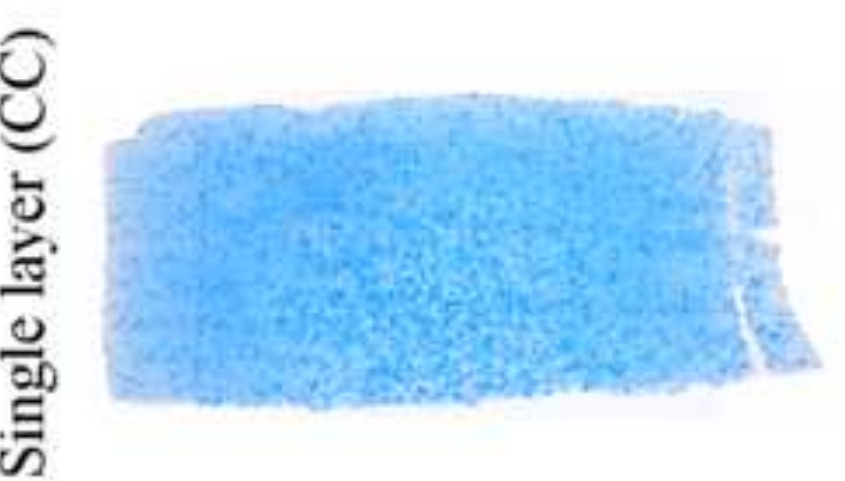

Alizarin red
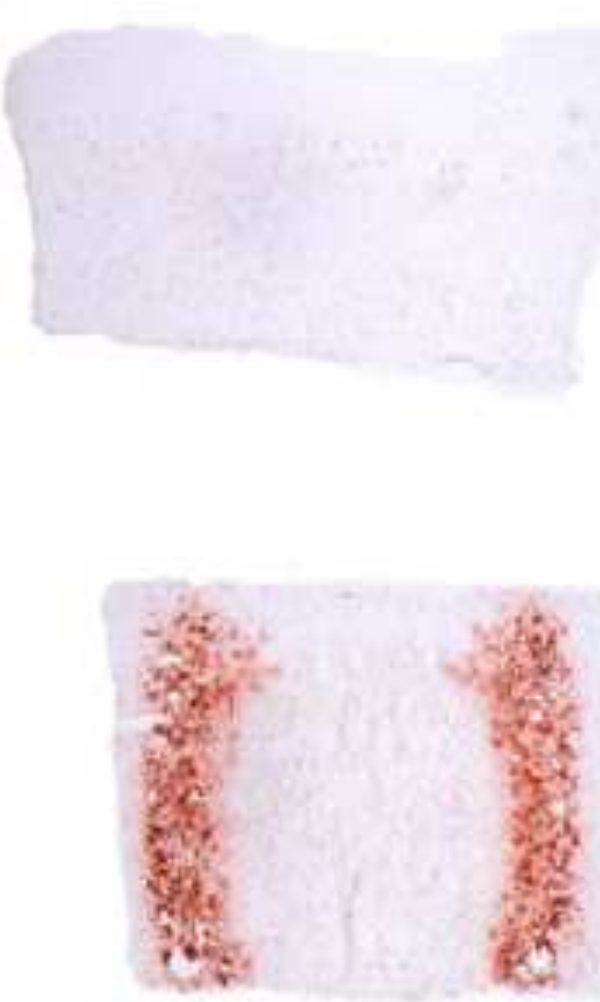

Picro-sirius red
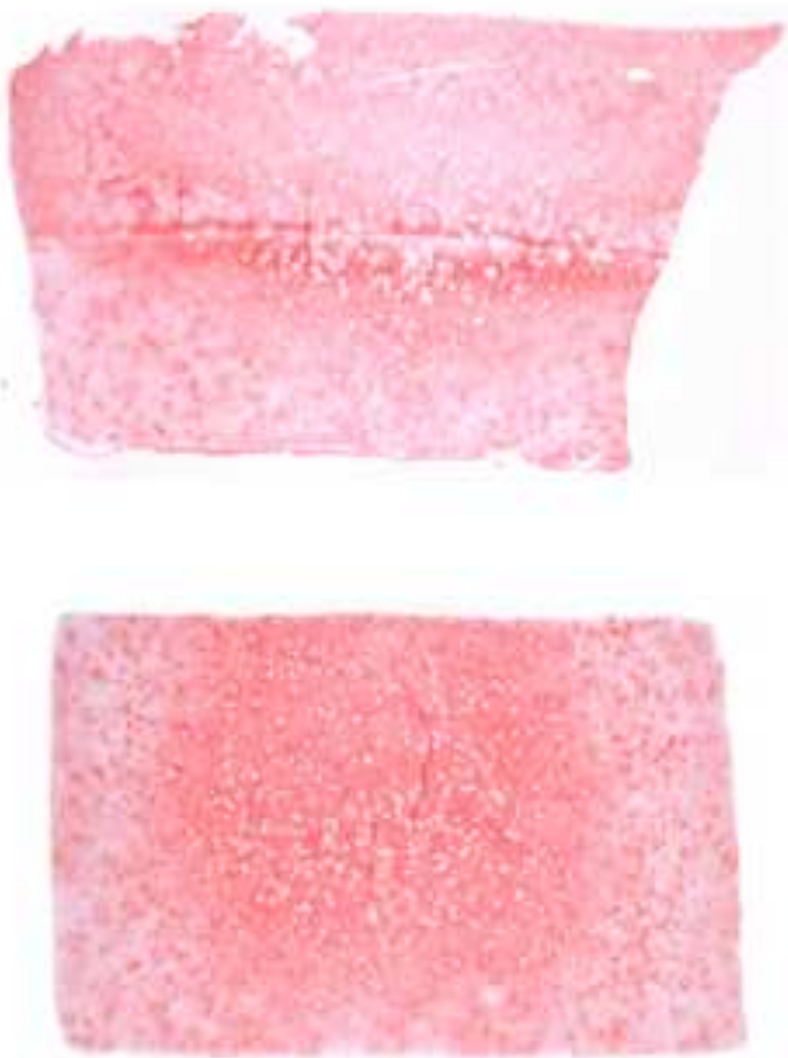
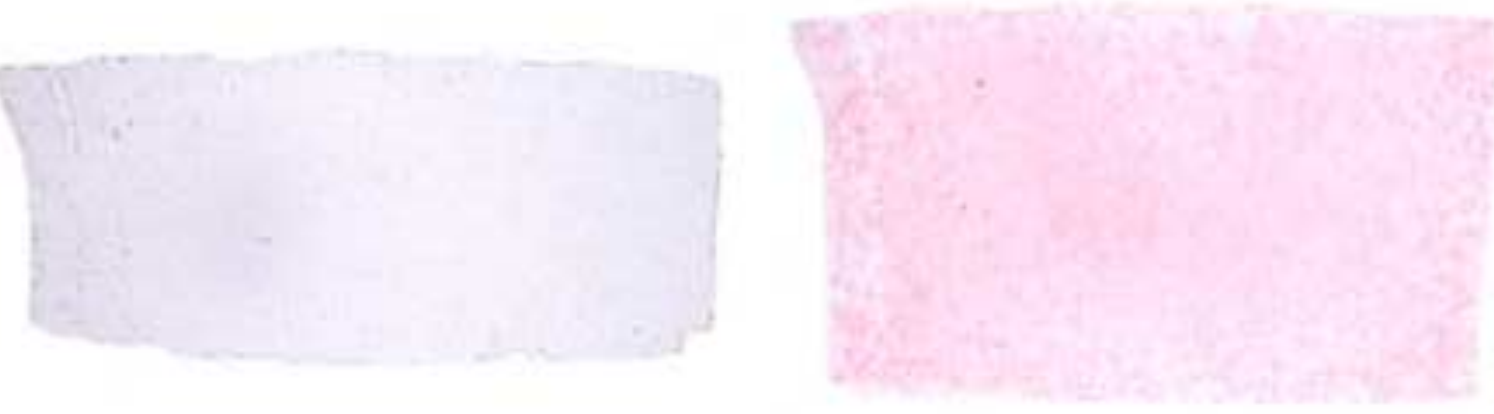
Click here to download high resolution image

\section{Collagen I}
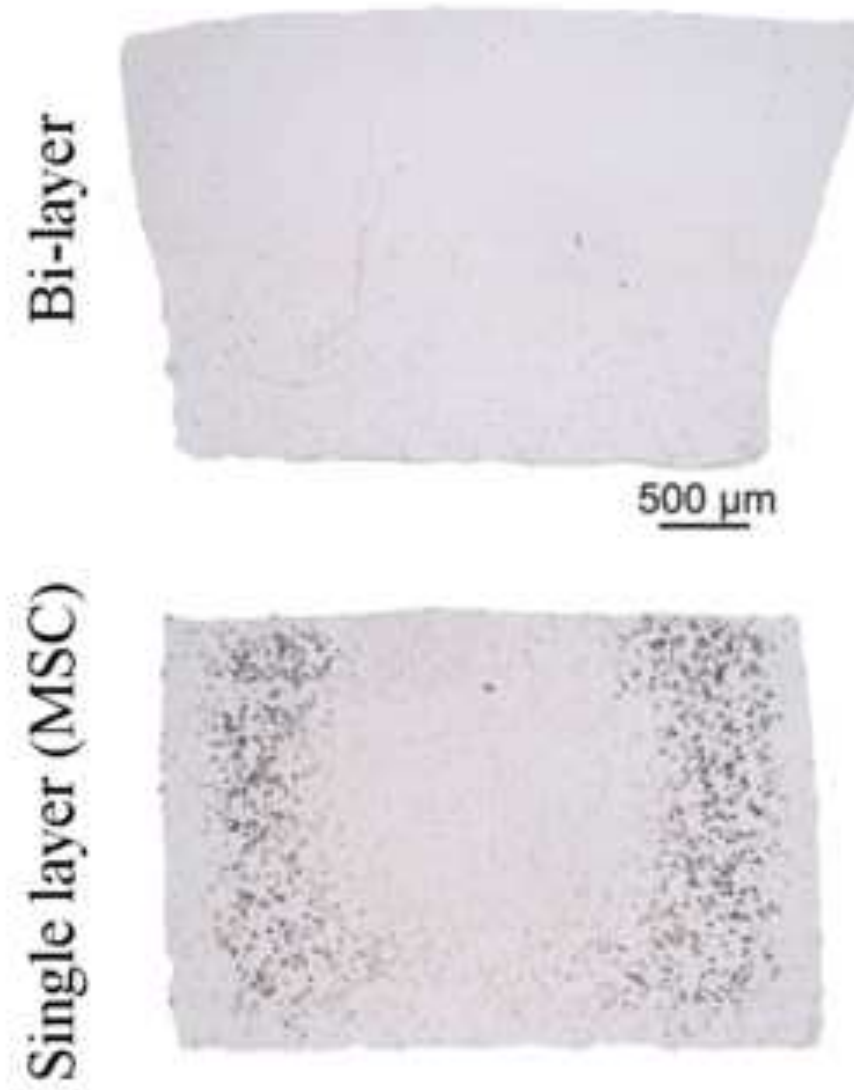

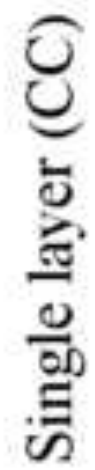

Collagen II
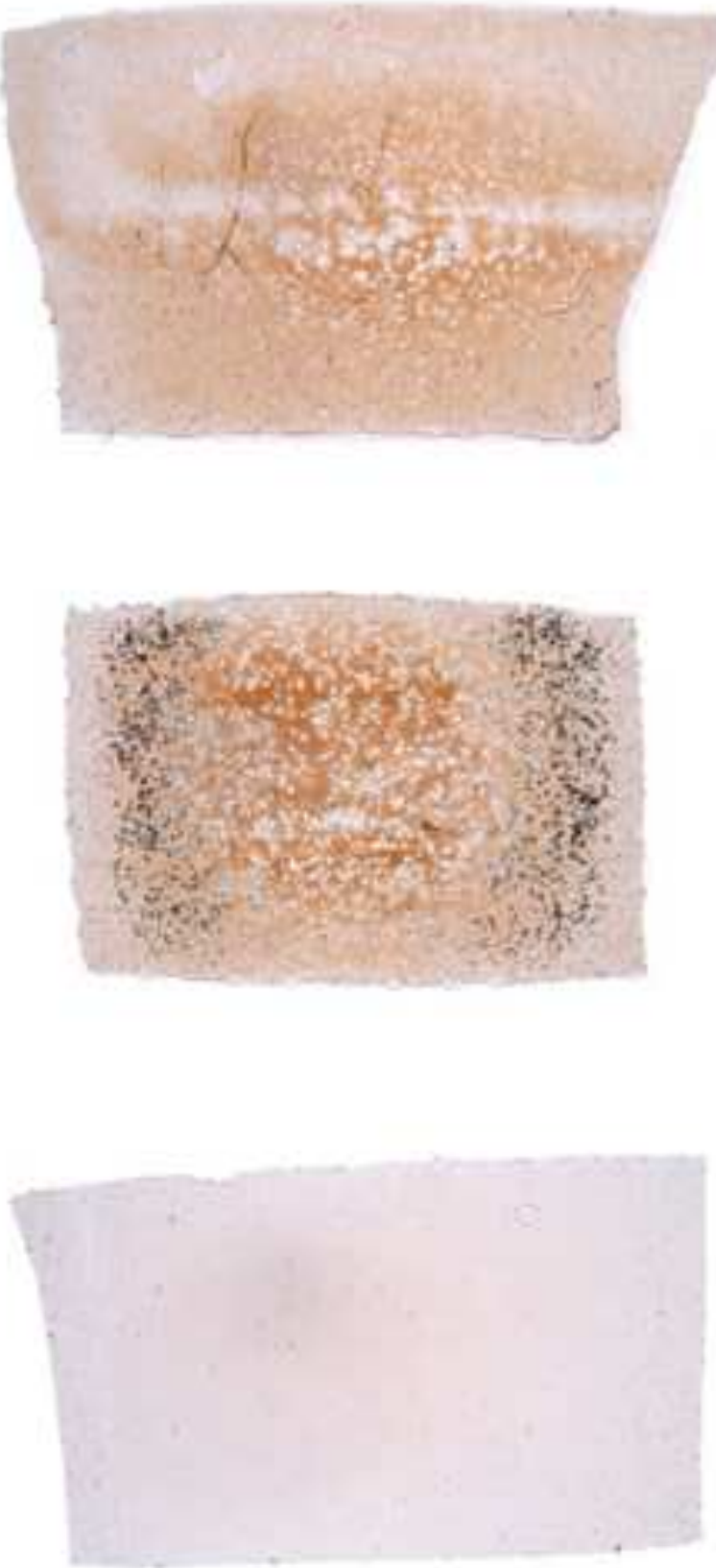

Collagen X
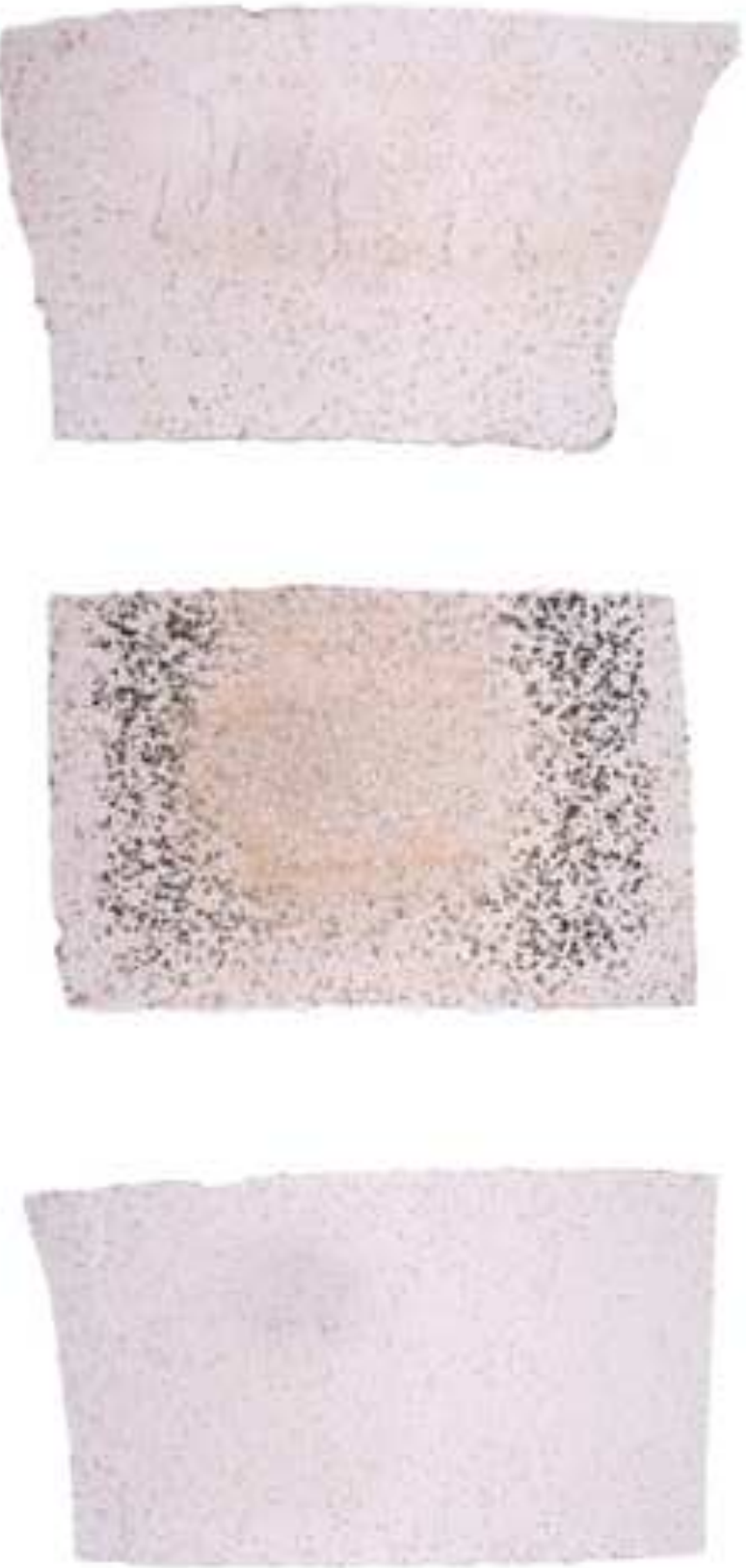
Alcian blue
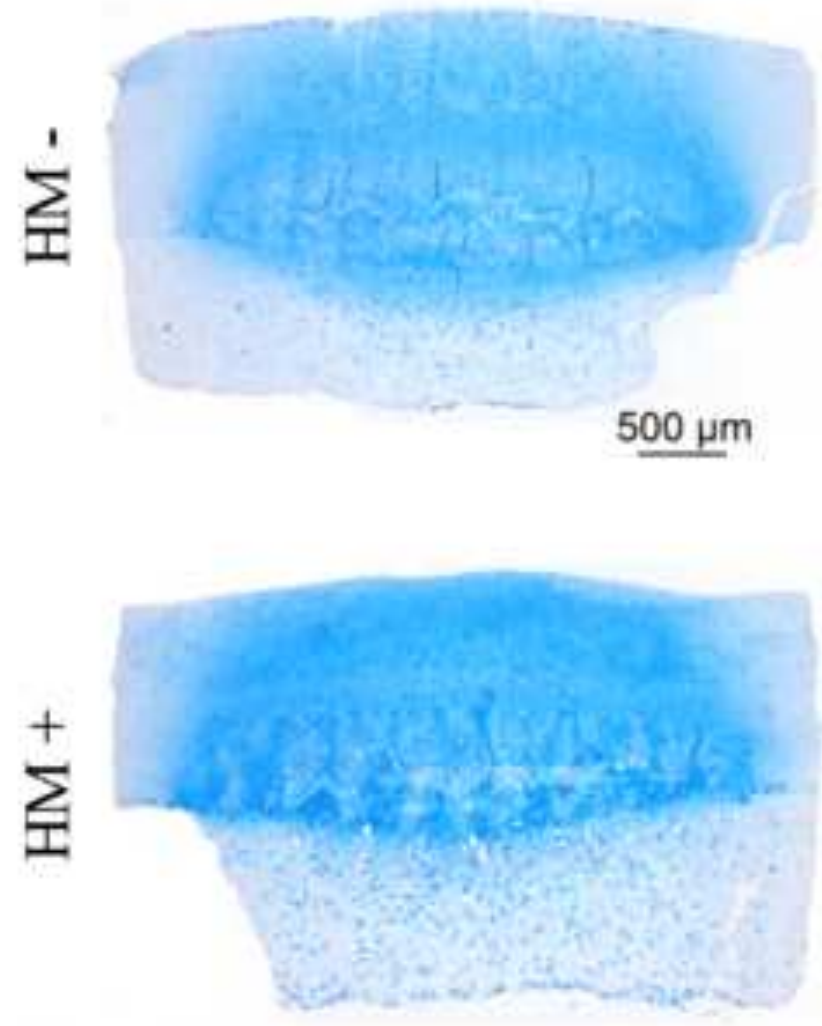

(a)

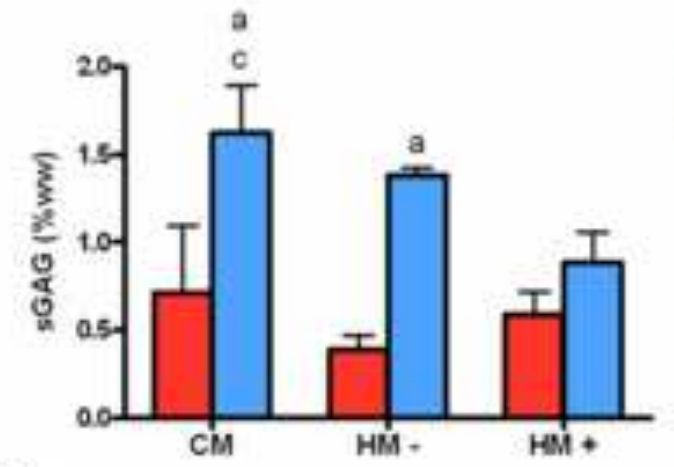

(b)

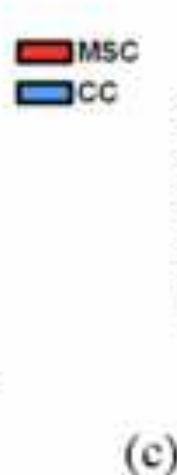

(c)
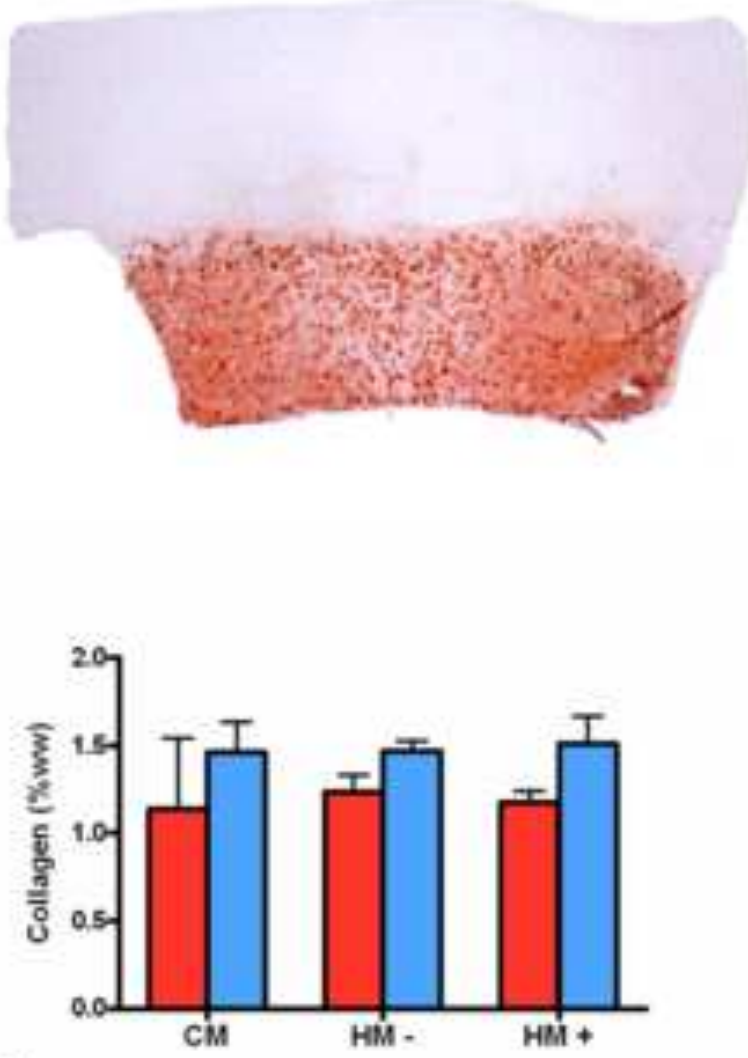

(d)

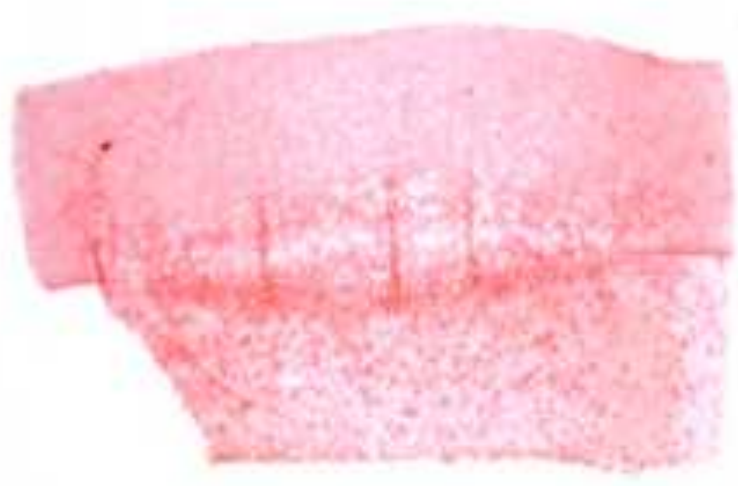

\section{Picro-sirius red}
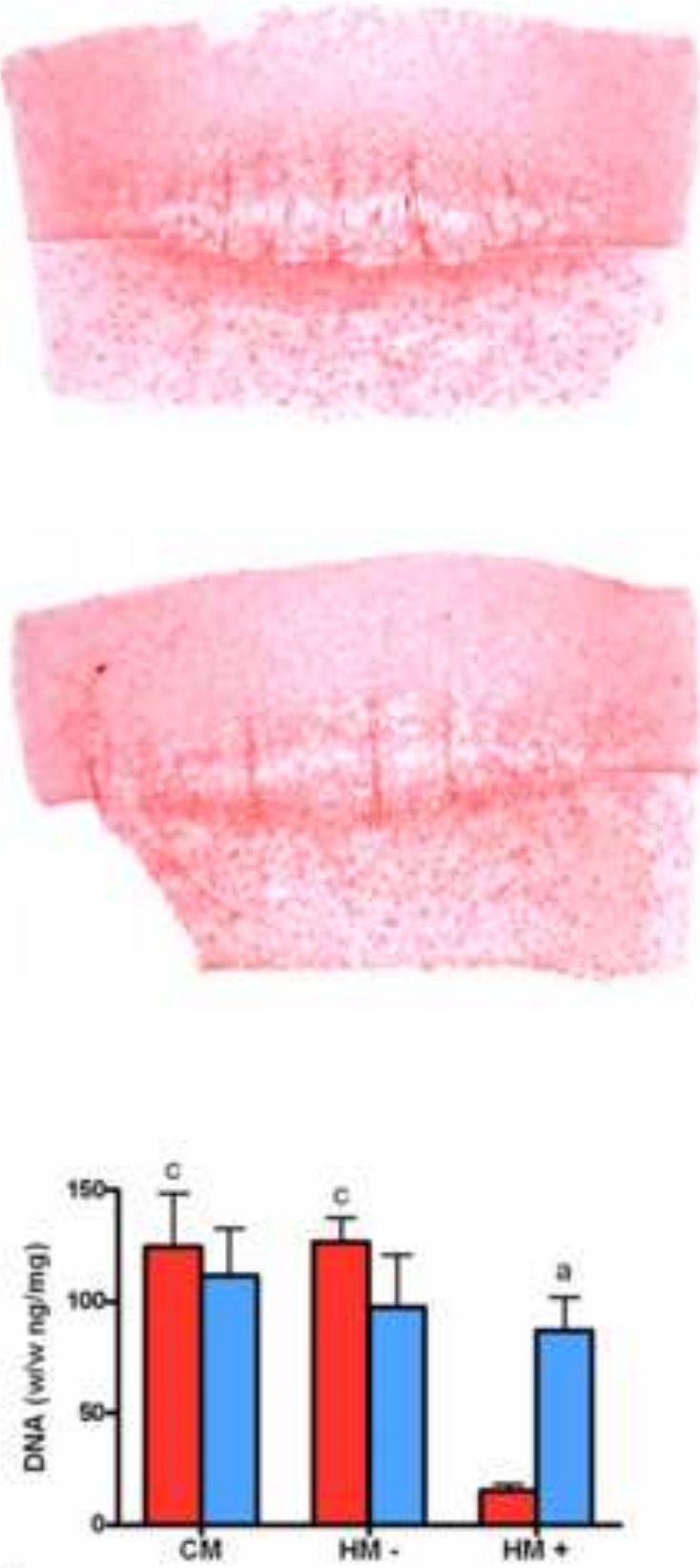
Click here to download high resolution image

\author{
Pre-Implantation

\section{Bi-layer} \\ Single layer (MSC)
}
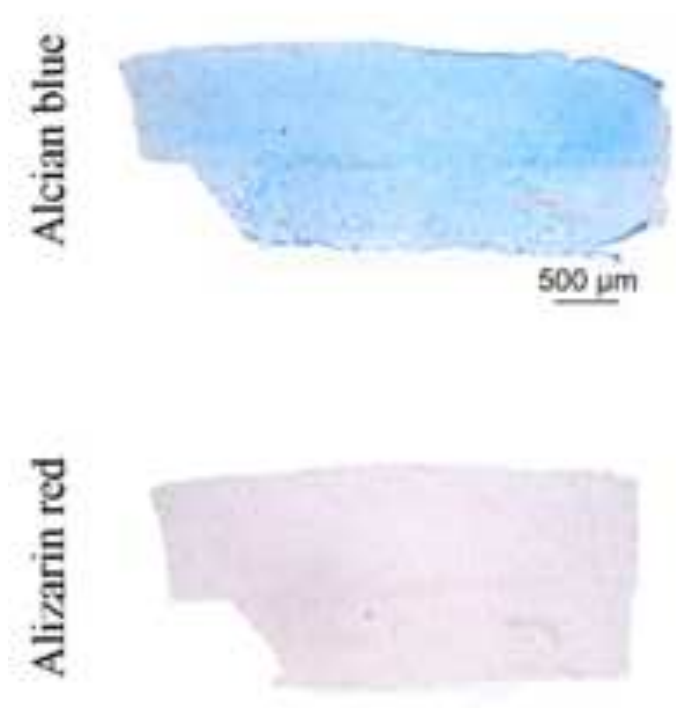

(a)
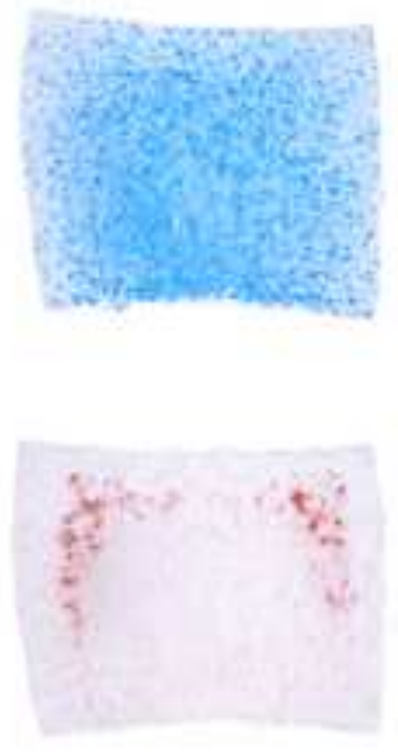

른

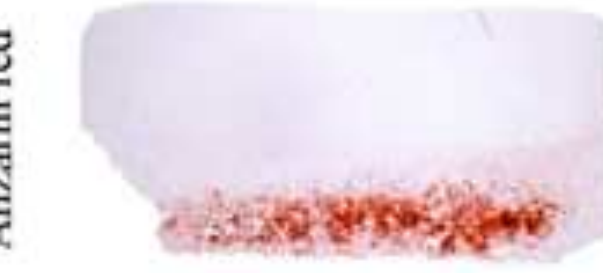

$\Xi$

(b)

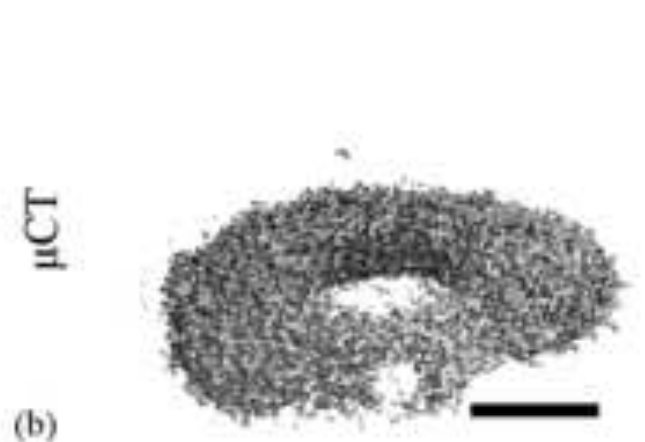

Single layer (MSC)
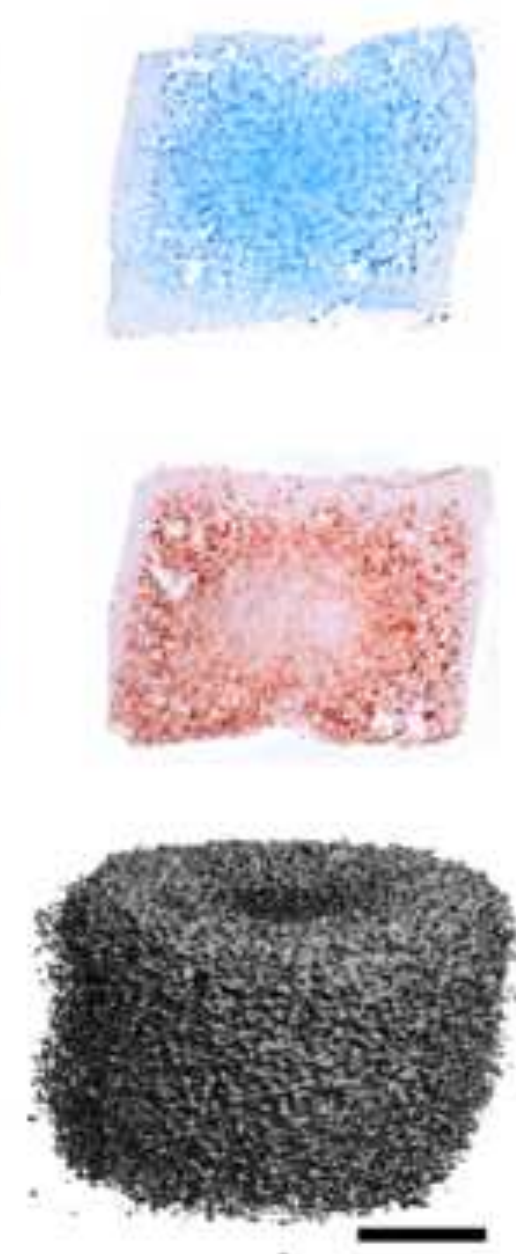

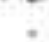


Click here to download high resolution image

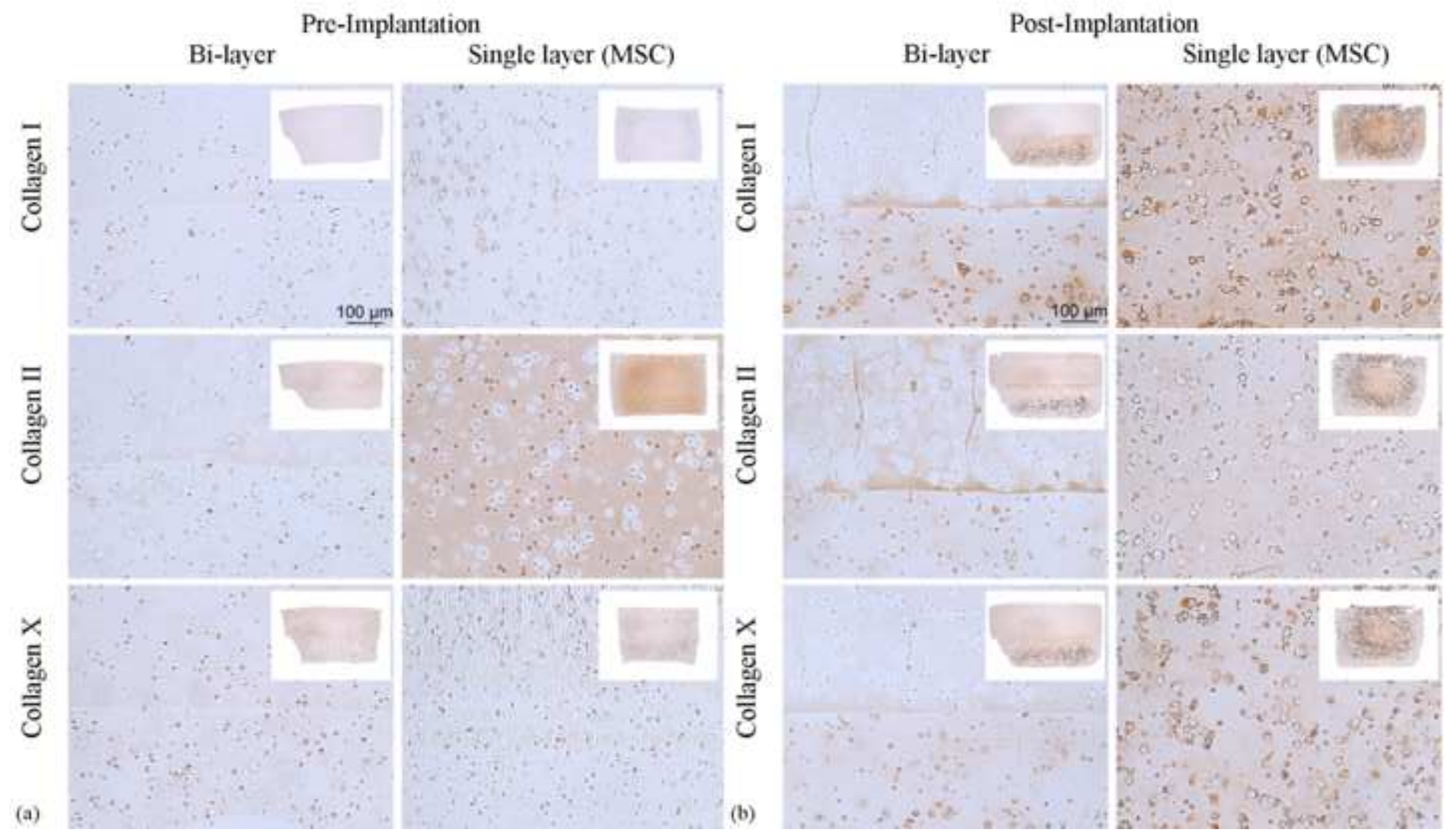

(a) 